\title{
Particles under stress: ultrasonication causes size and recovery rate artifacts with soil-derived POM but not with microplastics
}

\author{
Frederick Büks ${ }^{1}$, Gilles Kayser ${ }^{2}$, Antonia Zieger ${ }^{1}$, Friederike Lang ${ }^{2}$, and Martin Kaupenjohann ${ }^{1}$ \\ ${ }^{1}$ Chair of Soil Science, Department of Ecology, Technische Universität Berlin, 10587 Berlin, Germany \\ ${ }^{2}$ Chair of Soil Ecology, University of Freiburg, 79085 Freiburg im Breisgau, Germany
}

Correspondence: Frederick Büks (frederick.bueks@tu-berlin.de)

Received: 3 June 2020 - Discussion started: 16 June 2020

Revised: 2 November 2020 - Accepted: 21 November 2020 - Published: 11 January 2021

\begin{abstract}
The breakdown of soil aggregates and the extraction of particulate organic matter (POM) by ultrasonication and density fractionation is a method widely used in soil organic matter (SOM) analyses. It has recently also been used for the extraction of microplastic from soil samples. However, the investigation of POM physiochemical properties and ecological functions might be biased if particles are comminuted during the treatment. In this work, different types of POM, which are representative of different terrestrial ecosystems and anthropogenic influences, were tested for their structural stability in the face of ultrasonication in the range of 0 to $500 \mathrm{~J} \mathrm{~mL}^{-1}$. The occluded particulate organic matter (oPOM) of an agricultural and forest soil as well as pyrochar showed a significant reduction of particle size at $\geq 50 \mathrm{~J} \mathrm{~mL}^{-1}$ by an average factor of $1.37 \pm 0.16$ and a concurrent reduction of recovery rates by an average of $21.7 \pm 10.7 \%$ when being extracted. Our results imply that increasing ultrasonication causes increasing retention of POM within the sedimenting phase, leading to a misinterpretation of certain POM fractions as more strongly bound oPOM or part of the mineral-associated organic matter (MOM). This could, for example, lead to a false estimation of physical stabilization. In contrast, neither fresh nor weathered polyethylene (PE), polyethylene terephthalate (PET) and polybutylene adipate terephthalate (PBAT) microplastics showed a reduction of particle size or the recovery rate after application of ultrasound. We conclude that ultrasonication applied to soils has no impact on microplastic size distribution and thus provides a valuable tool for the assessment of microplastics in soils and soil aggregates.
\end{abstract}

\section{Introduction}

The mechanical disintegration of soil aggregates by use of ultrasonication following the method of Edwards and Bremner (1967a) and subsequent density fractionation of particulate organic matter is widely used in the assessment of soil organic matter (SOM) stability. This includes characteristics such as aggregate composition and stability (Edwards and Bremner, 1967b), the constitution of SOM pools (Golchin et al., 1994), the stabilization of SOM in forest ecosystems (Graf-Rosenfellner et al., 2016) and the occlusive strength of particulate organic matter (POM) (Büks and Kaupenjohann, 2016). Ultrasonication is also applied to assess quantities and qualities of anthropogenic contaminants such as microplastics (Zhang and Liu, 2018; Zhang et al., 2018).

In studies on soil carbon pools, ultrasound is applied to a soil slurry to break down soil aggregates. The disaggregation allows density fractionation of the free and occluded light fractions (fLF and oLF), which largely consist of material with densities below the fractionation medium, from the heavy fraction (HF), which has higher densities. These operational fractions largely correspond to the free particulate organic matter (fPOM), the occluded particulate organic matter (oPOM) and the mineral-associated organic matter (MOM). This organic matter is assigned to the labile, intermediate and stable carbon pool, respectively, and has turnover times of $<1$ year (labile) to several thousands of years (stable) (von Lützow et al., 2007).

Furthermore, the extracted POM fractions may contain not only natural but also anthropogenic components such as microplastic. Recent studies have reported soil microplastic concentrations between $1 \mathrm{mg} \mathrm{kg}^{-1}$ dry soil at less contami- 
nated sites and 2 to 4 orders of magnitude above in samples from highly contaminated industrial areas (Fuller and Gautam, 2016; Rezaei et al., 2019). The agricultural applications of sewage sludge, wastewater, compost, as well as plastic mulching and the input of road and tire wear, are discussed as important entry pathways to soils (Bläsing and Amelung, 2018). These origins of MP are characterized by a different composition of the size and shape of the extracted items (e.g., Zhang and Liu, 2018; Ding et al., 2020). In laboratory experiments, MP in the observed size range was shown to influence soil biogeochemical properties such as water-holding capacity, soil structure, microbial activity and the health of soil biota, with a strong dependence on the size and shape of the applied particles (de Souza Machado et al., 2018; Büks et al., 2020). Furthermore, the mobility within the soil pore space and preferential flow channels, which is crucial for the accessibility of soil microplastic to groundwaters and surface waters, is also highly dependent on particle size (O'Connor et al., 2019; Zubris and Richards, 2005). It is therefore a very topical task for both the impact assessment of given contaminations in landscapes and the design of robust experimental setups to have extraction methods with high yield and a low alteration of microplastic size and shape.

The common method of ultrasonication is carried out with a piezoelectric converter, which uses electric energy to generate axial vibration of a sonotrode, which is dipped into a flask containing a fluid and a submerged soil sample. The oscillating sonotrode emits acoustic pulses within the fluid. In front of the shock waves the medium is compressed, and the increased pressure causes an increased gas solubility. Behind the wave the medium relaxes and the pressure drops below the normal level, leading to an explosive outgassing (Ince et al., 2001). This so-called cavitation effect produces lots of exploding microbubbles between particles and within cavities of the soil matrix, generating very local pressure peaks of 200 to $500 \mathrm{~atm}$ accompanied by temperatures of 4200 to $5000 \mathrm{~K}$ (Ince et al., 2001). It provokes the detachment of physiochemical bondings between soil primary particles and soil aggregates and, thus, causes disaggregation. Depending on the type and settings of the device, the vibration frequency can vary up to $10000 \mathrm{kHz}$, but low frequencies around 20 to $100 \mathrm{kHz}$ are recommended for soil aggregate dispersion to avoid chemical alteration of OM, and the use of $40 \mathrm{kHz}$ is very common (Kaiser and Berhe, 2014; Graf-Rosenfellner et al., 2018).

As an artifact of the method, ultrasonication is known to provide mechanical and thermal stress strong enough to comminute mineral particles at energy levels $>700 \mathrm{~J} \mathrm{~mL}^{-1}$ (Kaiser and Berhe, 2014). Also, the destructive influence on POM was tested in different studies and appears even at energy levels much lower than $700 \mathrm{~J} \mathrm{~mL}^{-1}$. Without application of a solid mineral matrix, Balesdent et al. (1991) found $>60 \%$ of the POM in suspension comminuted after application of $300 \mathrm{~J} \mathrm{~mL}^{-1}$. Amelung and Zech (1999) treated natural soils with 0 to $1500 \mathrm{~J} \mathrm{~mL}^{-1}$ and performed a separa- tion into size fractions of $<20,20$ to 250 and $>250 \mu \mathrm{m}$. At $\geq 100 \mathrm{~J} \mathrm{~mL}^{-1}$ POM was transferred from the $>250$ to the $<20 \mu \mathrm{m}$ fraction. In a similar manner, Yang et al. (2009) measured the mass and soil organic carbon (SOC) content of sand, silt and clay sized particle fractions in natural soils using an unconventional pulse/non-pulse ultrasonication technique. The authors derived the comminution of POM at $>600 \mathrm{~J} \mathrm{~mL}^{-1}$. Oorts et al. (2005) added ${ }^{13} \mathrm{C}$-enriched straw to natural soils and could show that larger amounts of POM were redistributed at $450 \mathrm{~J} \mathrm{~mL}^{-1}$ when its degree of decomposition was higher. In conclusion, those studies consistently found a comminution of POM by ultrasonic treatment, which appears, however, at very different energy levels and is likely affected by the aggregation regime (suspended without mineral matrix, added as PPOM, occluded within natural soils), direct or indirect quantification of POM, and the type of POM.

The aim of this work was to test how susceptible different types of POM are to comminution by ultrasonic treatment under standardized conditions. We embedded three types of POM (farm oPOM, forest oPOM and pyrochar, applied as an analog for soil black carbon and biochar amendments) and also six differently weathered microplastics (fresh and weathered low-density polyethylene (LD-PE), polyethylene terephthalate (PET) as well as polybutylene adipate terephthalate (PBAT), a common biodegradable material) into a fine sand matrix. Then, we treated these mixtures with 0 , $10,50,100$ and $500 \mathrm{~J} \mathrm{~mL}^{-1}$, re-extracted the organic particles with density fractionation, and measured their recovery rates and particle size distributions. The sand matrix was used only to simulate the influence of pore space on cavitation and, thus, our simplified approach excluded broadly varying POM-mineral interactions resulting from aggregation processes in natural soil samples.

In advance of the treatment, the nine materials showed different mechanical stabilities. Unlike all six types of plastic particles, the occluded POM and the pyrochar were easy to grind between two fingers and therefore assumed to be prone to ultrasonication. An examination of the recent literature on microplastic extraction from soils showed that the stability of microplastic in the face of ultrasound has not been studied yet, neither with weathered nor juvenile material. Experiments with polymer-based adsorber resins indicated fractures on microbead surfaces after treatment with $100 \mathrm{~J} \mathrm{~s}^{-1}$ at $40 \mathrm{kHz}$ for $70 \mathrm{~min}$ (Breitbach et al., 2002). When exposed to the environment, plastic undergoes weathering by UV radiation, mechanical comminution, microbial decay and chemical alteration (Kale et al., 2015; Andrady et al., 2017), which leads to embrittlement. We therefore hypothesized that unweathered microplastic particles will be prone to ultrasonic treatment to a degree less than weathered microplastic and much less than pyrochar or natural oPOM. 


\section{Material and methods}

\subsection{Preparation of POM}

The farm and forest oPOM were extracted from air-dried soil aggregates of 630 to $2000 \mu \mathrm{m}$ in diameter sampled in 10 to $20 \mathrm{~cm}$ depth from an organic horticulture near Oranienburg (Brandenburg; 52 $46^{\prime} 54^{\prime \prime} \mathrm{N}, 13^{\circ} 11^{\prime} 50^{\prime \prime} \mathrm{E}$, sandy texture, $C_{\text {org }}=49.3 \mathrm{~g} \mathrm{~kg}^{-1}$, pH 5.8) and a spruce-beech mixed forest near Bad Waldsee (Baden-Württemberg; 47 $50^{\prime} 59^{\prime \prime} \mathrm{N}$, $9^{\circ} 41^{\prime} 30^{\prime \prime} \mathrm{E}$, texture S14, $\left.C_{\text {org }}=73.2 \mathrm{~g} \mathrm{~kg}^{-1}, \mathrm{pH} 3.4\right)$. The extraction was performed by use of a density fractionation in $1.6 \mathrm{~g} \mathrm{~cm}^{-3}$ dense sodium polytungstate (SPT) solution: in 12 -fold replication, $120 \mathrm{~mL}$ of SPT solution was added to $30 \mathrm{~g}$ of aggregates in a $200 \mathrm{~mL}$ PE bottle. The sample was stored for $1 \mathrm{~h}$ to allow the SPT solution to infiltrate the aggregates and was then centrifuged at $3500 \mathrm{G}$ for $26 \mathrm{~min}$. The floating free particulate organic matter (fPOM) was removed by use of a water-jet pump and discarded. The remaining sample was refilled to $120 \mathrm{~mL}$ with SPT solution and sonicated for $30 \mathrm{~s}\left(\approx 10 \mathrm{~J} \mathrm{~mL}^{-1}\right)$ by use of a sonotrode (Branson@ Sonifier 250) in order to flaw the structure of macroaggregate $(>250 \mu \mathrm{m})$. Then, centrifugation and removal of the oPOM were executed as for the PPOM. The gained oPOM was filtered with a $0.45 \mu \mathrm{m}$ cellulose acetate membrane filter, washed 3 to 5 times with $200 \mathrm{~mL}$ deionized water within the filter device until the rinse had an electrical conductivity of $<50 \mu \mathrm{S} \mathrm{cm}^{-1}$, removed from the filter by rinsing with deionized water, collected and gently dried for $48 \mathrm{~h}$ at $40^{\circ} \mathrm{C}$. At the end, the oPOM was sieved to $2000 \mu \mathrm{m}$, residues with elongated shape were cut by a sharp knife, sieved again and pooled to one oPOM sample. The pyrogenic char sample (made from pine wood, pyrolyzed at $850^{\circ} \mathrm{C}$ for $0.5 \mathrm{~h}$ by PYREG $^{\circledR} \mathrm{GmbH}$ ) was dried for $24 \mathrm{~h}$ at $105^{\circ} \mathrm{C}$, ground in a mortar and sieved to $<630 \mu \mathrm{m}$. The microplastics (LDPE, PET and PBAT) were made from plastic films by repeated milling (Fritsch Pulverisette 14) with liquid nitrogen and sieved to $<500 \mu \mathrm{m}$. Then, half of each sample was weathered for $96 \mathrm{~h}$ at $38^{\circ} \mathrm{C}, 1000 \mathrm{~W} \mathrm{~m}^{-2}$ (solar spectrum, 280 to $3000 \mathrm{~nm}$ ) and a relative air humidity of $50 \%$ following DIN EN ISO 4892-2/3, which is the international industry standard for testing artificial weathering of polymerbased materials (Pickett, 2018).

\subsection{Mechanical stress treatment}

In order to test their stability against ultrasonication, the nine POM types (farm and forest oPOM and pyrochar as well as fresh and weathered LD-PE, PET and PBAT) were each exposed in triplicates to different mechanical stress levels $\left(0,10,50,100\right.$ and $\left.500 \mathrm{~J} \mathrm{~mL}^{-1}\right)$. The treatment with $0 \mathrm{~J} \mathrm{~mL}^{-1}$ was used as a control with no mechanical agitation, and $10 \mathrm{~J} \mathrm{~mL}^{-1}$ represents a gentle stimulation, which is suggested not to disaggregate soil structure (Kaiser and Berhe, 2014). Macroaggregates are prone to $50 \mathrm{~J} \mathrm{~mL}^{-1}$, and
100 to $500 \mathrm{~J} \mathrm{~mL}^{-1}$ marks the range of microaggregate disaggregation, as many studies stated full disaggregation of soils after application of $\sim 500 \mathrm{~J} \mathrm{~mL}^{-1}$ (Kaiser and Berhe, 2014). Larger values were ruled out, although some studies applied energy levels above $500 \mathrm{~J} \mathrm{~mL}^{-1}$, like that of Pronk et al. (2011), who could show that silt-sized microaggregates were not dispersed at energy levels $\leq 800 \mathrm{~J} \mathrm{~mL}^{-1}$. However, small microaggregates often contain little or no POM (Tisdall, 1996), and energies $>710 \mathrm{~J} \mathrm{~mL}^{-1}$ cause physical damage on mineral particles (Kaiser and Berhe, 2014). Therefore we focus on the range of 0 to $500 \mathrm{~J} \mathrm{~mL}^{-1}$ as a safe space for the extraction of POM with no other known artifacts.

We chose acid-washed and calcinated fine sand to simulate the soil mineral matrix. This texture can be easily suspended by ultrasonication (coarse sand cannot), has a low tendency to coat POM or coagulate (like clay does) and shows a fast sedimentation when the sample is centrifuged. Fine sand, moreover, represents soils that originated from Weichselian sanders or eolian sand deposition. In this methodical paper, our aim, however, was not to simulate a set of soil textures, but to have a proof of concept to find out whether natural or artificial POM is damaged by ultrasonication. Then, quantities of $1 \% w / w$ POM, and $0.5 \% w / w$ in the case of the oPOM, were embedded into the fine sand matrix.

These artificial soils (each $20 \mathrm{~g}$ ) were stored in $100 \mathrm{~mL}$ of $1.6 \mathrm{~g} \mathrm{~cm}^{-3}$ dense SPT solution for $1 \mathrm{~h}$ in $200 \mathrm{~mL}$ PE bottles, which did not show measurable release of plastic fragments due to sonication in preliminary tests with a pure fine sand matrix (data not shown). Mechanical stress was applied by use of a sonotrode (Branson $\odot$ Sonifier 250) as described by Büks and Kaupenjohann (2016). The sonication times corresponding to $0,10,50,100$ and $500 \mathrm{~J} \mathrm{~mL}^{-1}$ were determined by means of the sonotrode's energy output calculated following North (1976). After the ultrasonic treatment, samples were centrifuged at $3500 \mathrm{G}$ for $26 \mathrm{~min}$. The floated POM was removed by use of a water-jet pump, separated and cleaned by rinsing with deionized water on a $0.45 \mu \mathrm{m}$ cellulose acetate membrane filter until the electrical conductivity of the rinse went below $50 \mu \mathrm{S} \mathrm{cm}^{-1}$, and then lyophilized.

\subsection{Determination of recovery rates}

After lyophilization, the recovery rate $R=m_{\mathrm{t}} m_{0}^{-1}$ was determined by weighing and described as the ratio of the recovered POM mass after treatment $\left(m_{\mathrm{t}}\right)$ to the initial POM mass $\left(m_{0}\right)$ for all POM types and energy levels. The recovery rate of a certain energy level is assumed significantly different to the $0 \mathrm{~J} \mathrm{~mL}^{-1}$ level if a pairwise $t$ test results in $p<0.05(\mathrm{Ta}-$ ble 1).

\subsection{Measurement of particle sizes}

All samples continued to be used for particle sizing. After pre-trials have shown that mainly the hydrophobic particles (microplastics and pyrochar) coagulated in dis- 
tilled water, aggregation was avoided by suspension in $0.1 \% \mathrm{w} / v$ Tween $\odot 20$ detergent solution and vortexing following Katija et al. (2017). A total of 30 to $100 \mathrm{mg}$ of POM was suspended in $500 \mathrm{~mL} 0.1 \%$ Tween $\odot 20$ solution and size classified with a QICPIC image analysis device (Sympatec $\mathrm{GmbH}$, Clausthal-Zellerfeld, Germany) using a modified method from Kayser et al. (2019). Counts were grouped into 34 size classes from $<5.64$ to $1200-1826.94 \mu \mathrm{m}$ and plotted as cumulative histograms of each replicate and their mean values (Fig. 1a and b). As the primary criterion for the reduction in particle size, the first $10 \%$ and $50 \%$ quantile (median) values were compared by a pairwise $t$ test between $0 \mathrm{~J} \mathrm{~mL}^{-1}$ and each other energy level, respectively. As particle size reduction could be significant but still marginal in the case of a low variance between parallels and a low grade of comminution at the same time, the averaged comminution factor $(\mathrm{CF})$ was introduced. It is defined as

$\mathrm{CF}=\frac{\sum_{i}\left(\frac{x_{0, i}}{x_{i}}\right)}{i}$,

with $i$ the number of parallels, $x_{0, i}$ the quantile value of the $0 \mathrm{~J} \mathrm{~mL}^{-1}$ energy level and $x_{i}$ the value of the compared energy level. A sample is then assumed significantly different to the $0 \mathrm{~J} \mathrm{~mL}^{-1}$ control and not marginal if the $p$ value given by the $t$ test is $<0.05$ and the comminution factor is $>1.1$ for the $10 \%$ quantile, the median or both, while its standard deviation is $\mathrm{SD}<|\mathrm{CF}-1|$ (Table 2).

\subsection{Organic matter balance}

A second set of triplicates of pyrochar and farm soil oPOM were treated similarly at 0 and $500 \mathrm{~J} \mathrm{~mL}^{-1}$ to balance the complement of the recovered POM. For this purpose, the C concentration within the lyophilized sediment was measured by use of a CNS analyzer and converted to POM mass by use of the $\mathrm{C}$ content $(\%)$ of the respective organic matter. In addition, the mass gain of the cellulose acetate filters was measured after rinsing the sample and drying the filter at $70^{\circ} \mathrm{C}$ for $24 \mathrm{~h}$. The dissolved organic carbon (DOC) concentration of the filtrate was measured and converted to dissolved organic matter (DOM) by use of an assumed $50 \% \mathrm{C}$ content. The difference of these and the recovered fractions compared to the initial weight of organic particles is termed the balance loss during the extraction procedure (Table 3).

\section{Results}

\subsection{Resulting recovery rates}

All microplastic samples (LD-PE, PET and PBAT) show a constantly high recovery rate of about $97.1 \pm 2.5 \%$ on average over the whole range of applied energy levels. In sharp contrast, all other samples were decreasingly recovered along with increasing energy levels. Farmland POM, forest POM and pyrochar showed significant differences to the $0 \mathrm{~J} \mathrm{~mL}^{-1}$ treatment at $\geq 10, \geq 100$ and $\geq 100 \mathrm{~J} \mathrm{~mL}^{-1}$, respectively (Table 1).

\subsection{POM size distribution}

None of the plastics shows a significant reduction of particle size due to ultrasonic treatment within the $10 \%$ and $50 \%$ quantile. In contrast, at $\geq 100 \mathrm{~J} \mathrm{~mL}^{-1}$ the particle size of farm and forest oPOM was significantly reduced compared to the $0 \mathrm{~J} \mathrm{~mL}^{-1}$ treatment in both quantiles. Ultrasonic treatment also causes a significant comminution of pyrochar, but of mainly the smaller fraction indicated by the $10 \%$ quantile, which appeared at $\geq 50 \mathrm{~J} \mathrm{~mL}^{-1}$ and is only interrupted due to an outlier at $100 \mathrm{~J} \mathrm{~mL}^{-1}$. The $50 \%$ quantile data (median) remain insignificant (Fig. 1a and b, Table 2).

\subsection{Mass loss}

The treatment of pyrochar triplicates with $500 \mathrm{~J} \mathrm{~mL}^{-1}$ resulted in a recovery rate of $54.3 \pm 5.2 \%$ after density fractionation. In turn, $34.9 \pm 3.7 \%$ of the POM remained in the sediment, $0.6 \pm 0.1 \%$ into the DOM fraction and $<0.5 \%$ onto the filter, leading to a balance loss of $10.2 \pm 2.1 \%$ (Table 3). The respective data of farm oPOM are $54.6 \pm 1.9 \%$, $20.3 \pm 3.1 \%, 5.1 \pm 0.2 \%,<0.5 \%$ and $20.0 \pm 1.5 \%$. Samples treated with $0 \mathrm{~J} \mathrm{~mL}^{-1}$ instead showed a significantly higher recovery rate and lower retention compared to the $500 \mathrm{~J} \mathrm{~mL}^{-1}$ samples. In contrast, the balance loss remained constant between 0 and $500 \mathrm{~J} \mathrm{~mL}^{-1}$.

\section{Discussion}

Our experiments indicate that soil-derived oPOM and pyrochar embedded into a fine sand matrix are prone to comminution by ultrasonic treatment at energy levels of $\geq 50 \mathrm{~J} \mathrm{~mL}^{-1}$. These values are well below the 300 to $750 \mathrm{~J} \mathrm{~mL}^{-1}$ given in the literature for the complete disaggregation of various soils (Amelung and Zech, 1999; Oorts et al., 2005; Yang et al., 2009), namely in the range of values given for the destruction of macroaggregates (Amelung and Zech, 1999; Kaiser and Berhe, 2014). This underpins the former implications by some authors that ultrasonic treatment could lead to particle size artifacts. Microplastic, in contrast, shows a constant particle size distribution over all energy levels and seems to resist ultrasonication within the tested range of 0 to $500 \mathrm{~J} \mathrm{~mL}^{-1}$. The recovery of microplastics also shows a constantly high rate of nearly $100 \%$, which is not affected by the applied energy. In sharp contrast, the recovery rates of soil-derived POM and pyrochar decreased with increasing energies from $95.0 \%$ to $78.6 \%$ to $63.8 \%$ to $35.8 \%$, which became significant at 50 to $100 \mathrm{~J} \mathrm{~mL}^{-1}$ and therefore is quite parallel to observed size reduction.

The concurrent decrease of particle size and recovery rate of soil-derived POM and pyrochar and its absence after ul- 
Table 1. Recovery rates of natural POM and microplastics from after ultrasonic treatment with $0,10,50,100$ and $500 \mathrm{~J} \mathrm{~mL}-1(n=3)$. The (w) marks weathered plastics, $\mathrm{mv}$ the mean value and SD the standard deviation. Bold numbers are significantly different from the $0 \mathrm{~J}^{\mathrm{mL}}{ }^{-1}$ treatment by $p<0.05$.

\begin{tabular}{lrrrrr}
\hline \multirow{5}{*}{ Sample } & \multicolumn{5}{c}{ Recovery rate $[\% w / w]$} \\
\cline { 2 - 6 } & $\begin{array}{r}0 \mathrm{~J} \mathrm{~mL}^{-1} \\
\mathrm{mv} \pm \mathrm{SD}\end{array}$ & $\begin{array}{r}10 \mathrm{~J} \mathrm{~mL}^{-1} \\
\mathrm{mv} \pm \mathrm{SD}\end{array}$ & $\begin{array}{r}50 \mathrm{~J} \mathrm{~mL}^{-1} \\
\mathrm{mv} \pm \mathrm{SD}\end{array}$ & $\begin{array}{r}100 \mathrm{~J} \mathrm{~mL}^{-1} \\
\mathrm{mv} \pm \mathrm{SD}\end{array}$ & $\begin{array}{r}500 \mathrm{~J} \mathrm{~mL}^{-1} \\
\mathrm{mv} \pm \mathrm{SD}\end{array}$ \\
\hline Farm oPOM & $95.0 \pm 2.3$ & $\mathbf{8 0 . 8} \pm \mathbf{4 . 5}$ & $\mathbf{7 3 . 2} \pm \mathbf{6 . 1}$ & $\mathbf{7 2 . 3} \pm \mathbf{2 . 8}$ & $\mathbf{5 1 . 6} \pm \mathbf{7 . 2}$ \\
Forest oPOM & $89.3 \pm 5.4$ & $79.0 \pm 5.1$ & $76.9 \pm 8.4$ & $\mathbf{6 7 . 8} \pm \mathbf{3 . 6}$ & $\mathbf{4 8 . 7} \pm \mathbf{5 . 4}$ \\
Pyrochar & $93.5 \pm 10.1$ & $84.6 \pm 6.1$ & $78.1 \pm 2.5$ & $\mathbf{7 4 . 3} \pm \mathbf{1 . 9}$ & $\mathbf{6 3 . 8} \pm \mathbf{3 . 1}$ \\
LD-PE & $96.9 \pm 1.2$ & $97.3 \pm 1.0$ & $95.8 \pm 6.7$ & $99.9 \pm 1.9$ & $99.2 \pm 1.6$ \\
LD-PE (w) & $93.9 \pm 3.4$ & $96.5 \pm 1.2$ & $96.6 \pm 1.5$ & $98.9 \pm 3.0$ & $97.8 \pm 1.7$ \\
PET & $98.6 \pm 2.5$ & $94.0 \pm 1.6$ & $98.7 \pm 2.5$ & $98.5 \pm 2.0$ & $94.3 \pm 1.3$ \\
PET (w) & $96.2 \pm 2.5$ & $95.4 \pm 3.0$ & $97.0 \pm 2.0$ & $95.5 \pm 1.0$ & $96.4 \pm 3.3$ \\
PBAT & $99.6 \pm 2.5$ & $99.5 \pm 0.9$ & $90.9 \pm 13.8$ & $98.3 \pm 3.6$ & $98.2 \pm 0.9$ \\
PBAT (w) & $97.7 \pm 0.9$ & $99.3 \pm 1.9$ & $96.8 \pm 1.6$ & $96.6 \pm 1.7$ & $99.3 \pm 1.9$ \\
\hline
\end{tabular}
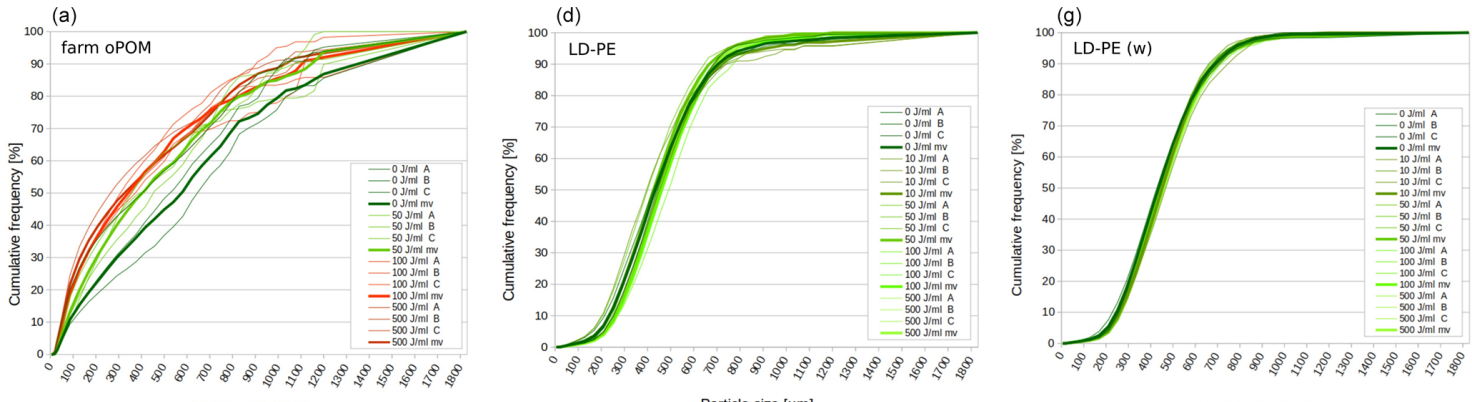

Particle size $[\mu \mathrm{m}$
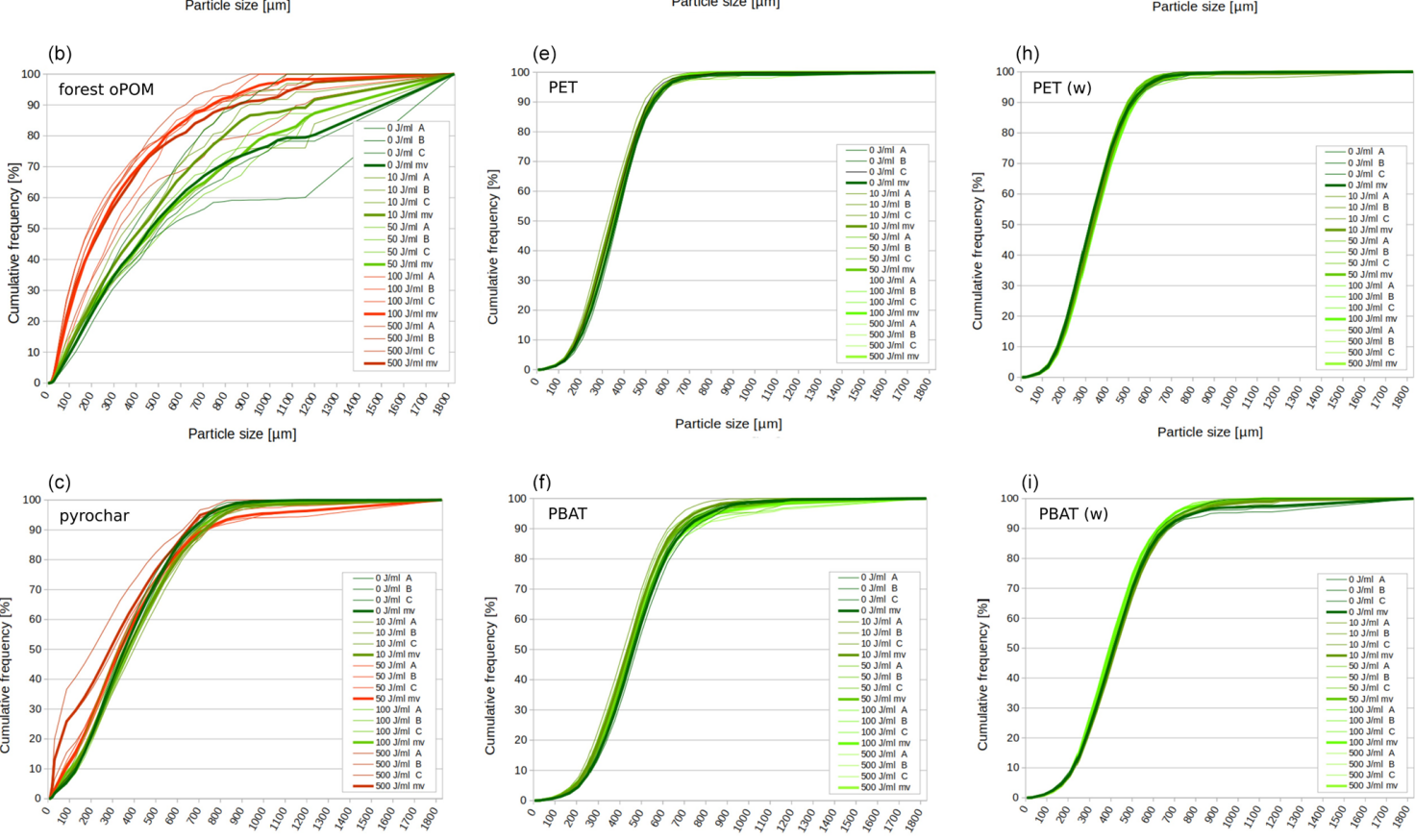

Particle size $[\mu \mathrm{m}]$

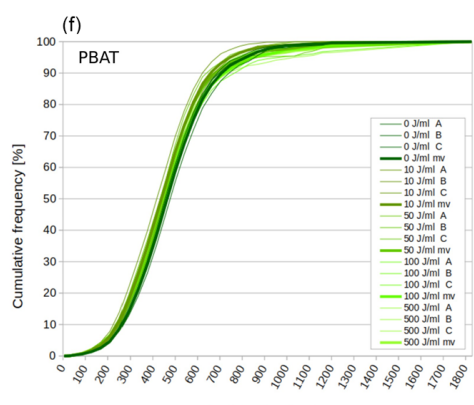

Particle size $[\mu \mathrm{m}]$

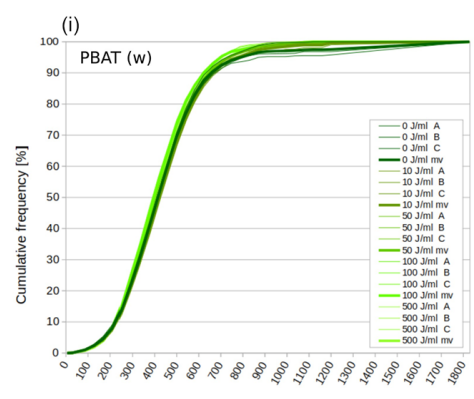

Particle size $[\mu \mathrm{m}]$

Figure 1. Particle size distribution of natural POM (a-c) and microplastics (d-i) after ultrasonic treatment with $0,10,50,100$ and $500 \mathrm{~J}^{\mathrm{mL}} \mathrm{L}^{-1}$ $\left(n=3\right.$ : A, B, C). Green graphs are similar to the $0 \mathrm{~J} \mathrm{~mL}^{-1}$ treatment $(p \geq 0.05$ or comminution factor $\leq 1.1)$, red graphs significantly different by $p<0.05$ and comminution factor $>1.1$. Bold lines represent mean values $(\mathrm{mv})$. The $(\mathrm{w})$ marks weathered plastics. 
Table 2. Particle size distribution (10\% and $50 \%$ quantile) and comminution factor of natural POM and microplastics after ultrasonic treatment with $0,10,50,100$ and $500 \mathrm{~J} \mathrm{~mL}^{-1}(n=3)$. The $(\mathrm{w})$ marks weathered plastics, mv the mean value and SD the standard deviation. Bold numbers are significantly different from the $0 \mathrm{~J} \mathrm{~mL}^{-1}$ treatment by $p<0.05$ and comminution factor $>1.1$.

\begin{tabular}{|c|c|c|c|c|c|}
\hline & & \multicolumn{2}{|c|}{ Size distribution } & \multicolumn{2}{|c|}{ Comminution factor } \\
\hline & & $10 \%$ quantile & $50 \%$ quantile & $10 \%$ quantile & $50 \%$ quantile \\
\hline POM type & $\mathrm{J} \mathrm{mL}^{-1}$ & $\mathrm{mv} \pm \mathrm{SD}$ & $\mathrm{mv} \pm \mathrm{SD}$ & $\mathrm{mv} \pm \mathrm{SD}$ & $\mathrm{mv} \pm \mathrm{SD}$ \\
\hline \multirow[t]{5}{*}{ Farm oPOM } & 0 & $82.90 \pm 9.46$ & $561.33 \pm 72.98$ & $1.00 \pm 0.00$ & $1.00 \pm 0.00$ \\
\hline & 10 & NA & NA & NA & NA \\
\hline & 50 & $72.31 \pm 15.39$ & $401.40 \pm 47.86$ & $1.17 \pm 0.15$ & $1.17 \pm 0.34$ \\
\hline & 100 & $53.40 \pm 2.61$ & $344.64 \pm 33.40$ & $1.56 \pm 0.26$ & $1.56 \pm 0.23$ \\
\hline & 500 & $47.21 \pm 2.46$ & $331.88 \pm 69.03$ & $1.76 \pm 0.21$ & $1.76 \pm 0.23$ \\
\hline \multirow[t]{5}{*}{ Forest oPOM } & 0 & $108.08 \pm 17.40$ & $476.26 \pm 79.01$ & $1.00 \pm 0.00$ & $1.00 \pm 0.00$ \\
\hline & 10 & $91.71 \pm 11.04$ & $422.27 \pm 68.13$ & $1.19 \pm 0.27$ & $1.17 \pm 0.36$ \\
\hline & 50 & $84.92 \pm 16.97$ & $485.08 \pm 41.44$ & $1.28 \pm 0.09$ & $0.98 \pm 0.14$ \\
\hline & 100 & $60.48 \pm 16.40$ & $233.11 \pm 58.78$ & $1.87 \pm 0.55$ & $2.18 \pm 0.80$ \\
\hline & 500 & $55.49 \pm 13.01$ & $244.41 \pm 70.33$ & $1.98 \pm 0.28$ & $2.02 \pm 0.48$ \\
\hline \multirow[t]{5}{*}{ Pyrochar } & 0 & $130.33 \pm 6.33$ & $355.79 \pm 16.19$ & $1.00 \pm 0.00$ & $1.00 \pm 0.00$ \\
\hline & 10 & $119.09 \pm 16.07$ & $369.18 \pm 39.01$ & $1.10 \pm 0.11$ & $0.97 \pm 0.15$ \\
\hline & 50 & $81.39 \pm 10.07$ & $333.41 \pm 9.59$ & $1.62 \pm 0.25$ & $1.07 \pm 0.08$ \\
\hline & 100 & $103.37 \pm 33.73$ & $371.92 \pm 19.99$ & $1.34 \pm 0.38$ & $0.96 \pm 0.09$ \\
\hline & 500 & $31.18 \pm 11.70$ & $284.35 \pm 67.85$ & $4.59 \pm 1.67$ & $1.30 \pm 0.28$ \\
\hline \multirow[t]{5}{*}{ LD-PE } & 0 & $235.15 \pm 19.46$ & $433.21 \pm 9.18$ & $1.00 \pm 0.00$ & $1.00 \pm 0.00$ \\
\hline & 10 & $236.54 \pm 29.80$ & $432.25 \pm 31.43$ & $1.00 \pm 0.06$ & $1.01 \pm 0.06$ \\
\hline & 50 & $237.80 \pm 28.51$ & $425.20 \pm 26.47$ & $1.01 \pm 0.20$ & $1.02 \pm 0.08$ \\
\hline & 100 & $263.23 \pm 6.87$ & $463.10 \pm 24.59$ & $0.89 \pm 0.05$ & $0.94 \pm 0.03$ \\
\hline & 500 & $266.29 \pm 5.32$ & $454.22 \pm 9.98$ & $0.88 \pm 0.06$ & $0.95 \pm 0.01$ \\
\hline \multirow[t]{5}{*}{ LD-PE (w) } & 0 & $245.69 \pm 15.39$ & $435.02 \pm 6.41$ & $1.00 \pm 0.00$ & $1.00 \pm 0.00$ \\
\hline & 10 & $260.20 \pm 5.64$ & $451.72 \pm 16.36$ & $0.94 \pm 0.04$ & $0.96 \pm 0.03$ \\
\hline & 50 & $265.51 \pm 1.55$ & $451.20 \pm 6.71$ & $0.93 \pm 0.06$ & $0.96 \pm 0.03$ \\
\hline & 100 & $253.61 \pm 7.67$ & $442.70 \pm 3.57$ & $0.97 \pm 0.08$ & $0.98 \pm 0.02$ \\
\hline & 500 & $262.94 \pm 3.25$ & $458.59 \pm 4.03$ & $0.93 \pm 0.06$ & $0.95 \pm 0.02$ \\
\hline \multirow[t]{5}{*}{ PET } & 0 & $193.66 \pm 11.91$ & $360.74 \pm 11.96$ & $1.00 \pm 0.00$ & $1.00 \pm 0.00$ \\
\hline & 10 & $180.15 \pm 7.97$ & $339.89 \pm 13.84$ & $1.08 \pm 0.12$ & $1.06 \pm 0.07$ \\
\hline & 50 & $179.69 \pm 5.09$ & $344.78 \pm 7.76$ & $1.08 \pm 0.09$ & $1.05 \pm 0.06$ \\
\hline & 100 & $162.59 \pm 29.24$ & $341.00 \pm 1.94$ & $1.21 \pm 0.19$ & $1.06 \pm 0.04$ \\
\hline & 500 & $181.14 \pm 7.12$ & $344.70 \pm 6.93$ & $1.07 \pm 0.08$ & $1.05 \pm 0.04$ \\
\hline \multirow[t]{5}{*}{ PET (w) } & 0 & $171.89 \pm 5.20$ & $321.46 \pm 4.19$ & $1.00 \pm 0.00$ & $1.00 \pm 0.00$ \\
\hline & 10 & $186.44 \pm 11.60$ & $332.81 \pm 7.80$ & $0.92 \pm 0.07$ & $0.97 \pm 0.01$ \\
\hline & 50 & $172.80 \pm 7.98$ & $324.73 \pm 7.55$ & $1.00 \pm 0.08$ & $0.99 \pm 0.04$ \\
\hline & 100 & $182.74 \pm 0.80$ & $340.28 \pm 7.11$ & $0.94 \pm 0.03$ & $0.95 \pm 0.03$ \\
\hline & 500 & $157.67 \pm 25.54$ & $331.51 \pm 9.52$ & $1.11 \pm 0.18$ & $0.97 \pm 0.04$ \\
\hline \multirow[t]{5}{*}{ PBAT } & 0 & $263.19 \pm 6.13$ & $464.20 \pm 11.93$ & $1.00 \pm 0.00$ & $1.00 \pm 0.00$ \\
\hline & 10 & $243.05 \pm 15.60$ & $437.71 \pm 18.57$ & $1.09 \pm 0.08$ & $1.06 \pm 0.04$ \\
\hline & 50 & $240.26 \pm 6.80$ & $441.55 \pm 9.41$ & $1.10 \pm 0.04$ & $1.05 \pm 0.05$ \\
\hline & 100 & $246.75 \pm 5.27$ & $455.51 \pm 5.37$ & $1.07 \pm 0.02$ & $1.02 \pm 0.04$ \\
\hline & 500 & $242.52 \pm 3.78$ & $452.18 \pm 11.85$ & $1.09 \pm 0.04$ & $1.03 \pm 0.05$ \\
\hline \multirow[t]{5}{*}{$\operatorname{PBAT}(w)$} & 0 & $223.53 \pm 6.06$ & $413.87 \pm 4.60$ & $1.00 \pm 0.00$ & $1.00 \pm 0.00$ \\
\hline & 10 & $225.56 \pm 6.97$ & $423.06 \pm 2.81$ & $0.99 \pm 0.06$ & $0.98 \pm 0.02$ \\
\hline & 50 & $225.22 \pm 2.92$ & $414.68 \pm 8.41$ & $0.99 \pm 0.04$ & $1.00 \pm 0.02$ \\
\hline & 100 & $220.13 \pm 1.97$ & $396.85 \pm 6.20$ & $1.02 \pm 0.03$ & $1.04 \pm 0.03$ \\
\hline & 500 & $224.71 \pm 5.53$ & $404.80 \pm 12.40$ & $1.00 \pm 0.03$ & $1.02 \pm 0.04$ \\
\hline
\end{tabular}

NA - not available. 
Table 3. Mass balance that indicates the fate of $\mathrm{OM}$ fractions during the ultrasonication/density fractionation treatment. Bold numbers indicate differences with $p<0.05$ after $t$ test between the 0 and $500 \mathrm{~J} \mathrm{~mL}^{-1}$ variant $(n=3)$.

\begin{tabular}{lrrrrr}
\hline POM (energy level) & Recovery (\%) & Retention $(\%)$ & Filter $(\%)$ & DOM $(\%)$ & Mass loss (\%) \\
\hline Pyrochar $\left(0 \mathrm{~J} \mathrm{~mL}^{-1}\right)$ & $\mathbf{7 9 . 6} \pm \mathbf{3 . 6}$ & $\mathbf{8 . 7} \pm \mathbf{0 . 3}$ & $<0.5$ & $\mathbf{0 . 3} \pm \mathbf{0 . 0}$ & $11.4 \pm 3.4$ \\
Pyrochar $\left(500 \mathrm{~J} \mathrm{~mL}^{-1}\right)$ & $\mathbf{5 4 . 3} \pm \mathbf{5 . 2}$ & $\mathbf{3 4 . 9} \pm \mathbf{3 . 7}$ & $<0.5$ & $\mathbf{0 . 6} \pm \mathbf{0 . 1}$ & $10.2 \pm 2.1$ \\
Farm oPOM $\left(0 \mathrm{~J} \mathrm{~mL}^{-1}\right)$ & $64.8 \pm 6.9$ & $\mathbf{8 . 3} \pm \mathbf{0 . 2}$ & $<0.5$ & $\mathbf{2 . 7} \pm \mathbf{0 . 0}$ & $24.1 \pm 6.8$ \\
Farm oPOM $\left(500 \mathrm{~J} \mathrm{~mL}^{-1}\right)$ & $54.6 \pm 1.9$ & $\mathbf{2 0 . 3} \pm \mathbf{3 . 1}$ & $<0.5$ & $\mathbf{5 . 1} \pm \mathbf{0 . 2}$ & $20.0 \pm 1.5$ \\
\hline
\end{tabular}

trasonic treatment of microplastics might indicate a causal relationship of these measures. The underlying process, however, has not been studied before. We assume a mechanism that prevents POM from density fractionation. This effect appeared in our experiment from energies around $50 \mathrm{~J} \mathrm{~mL}^{-1}$ with the beginning destruction of oPOM. As mentioned in Ince et al. (2001) and confirmed in Kaiser and Berhe (2014), ultrasonication-induced high temperature may reduce total C content due to oxidative reactions, but the balance loss, constant between 0 and $500 \mathrm{~J} \mathrm{~mL}^{-1}$ in both pyrochar and farm oPOM, implies that there is no burning of organic matter due to ultrasound treatment. Also the formation of large amounts of water-soluble molecules and colloids could be ruled out in our experiment. The recovery rate decreases to the same degree as the retention in the sediment increases when ultrasound is applied, while filter residues and lost DOM, which doubled on a low level, play a minor role. Extreme thermal conditions occurring during ultrasonication, however, may explain the increased retention of POM within the sediment. Sparse data on molecular alteration of organic materials due to ultrasonication showed the transformation of lignin, a major constituent of plant cell walls. One hour of treatment caused the formation of a high molecular weight fraction of about $35 \%$ of the lignin content with molecular weights increased 450-fold (Wells et al., 2013). This may also increase the density of lignin and lignin-like fractions in soil POM towards the density of the fractionation medium and reduce their recovery rate.

As a consequence of the reduction of the recovery rate, farmland, forest and pyrochar POM remain within a sandy matrix the stronger they are treated by ultrasound. If these findings are applied to ultrasonication/density fractionation of natural soils, not only an increasing number of particle size artifacts can be expected, but also the extraction of occluded POM is increasingly hindered at a certain energy level. After each extraction step, parts of the released oPOM remain within the sedimenting fraction, a carry-over artifact. This leads to an underestimation of the extracted oPOM fractions and an overestimation of the mineral-associated organic matter fraction (MOM), a natural part of the soil organic matter (SOM), which is adsorbed on mineral surfaces of the heavy fraction and mainly assumed to be molecular. According to our data, a reduction of recovery rates would appear at $10 \mathrm{~J} \mathrm{~mL}^{-1}$ in farmland soils and $100 \mathrm{~J} \mathrm{~mL}^{-1}$ in forest soils, as well as at $100 \mathrm{~J} \mathrm{~mL}^{-1}$ when extracting pyrochar particles. Thus, the artifact would affect the extraction of oPOM from microaggregates of all samples and also the extraction of oPOM from macroaggregates in farmland soils. However, further research has to elucidate whether these results can be applied to natural soil samples.

An overestimation would have an impact, for example, on the assessment of operationally defined carbon pools within landscapes: POM is assigned to carbon pools with turnover times orders of magnitude shorter then MOM, which endures hundreds of years. Misquantification of these pools, such as counting POM to the MOM as implied by this work, would have an influence on, for example, the estimation of SOM decomposition and $\mathrm{CO}_{2}$ emissions from land-use change. Carrying-over SOM from little to highly decomposed fractions also could alienate genuine $\mathrm{C}: \mathrm{N}$ ratios, which strongly differ between the functional carbon pools (Wagai et al., 2009). In respect to coming experiments, comminution and reduced recovery rate of the oPOM can possibly be avoided by not exceeding the energy levels mentioned here - or by determining a specific energy cut-off for each natural soil in preliminary studies. Regarding the application of higher energy levels, detailed investigation on the underlying mechanism is necessary to give such recommendations.

Microplastic particles, whether they are weathered following DIN ENISO4892-2/3 or pristine, are not prone to disruption by ultrasonic treatment, and their recovery rates are stable in a wide range of energy levels. We therefore assume that there will be significantly less carry-over of particles due to comminution when extracting microplastics from soils with ultrasonication/density fractionation. In consequence, the extractive performance is higher and subsequent particle size measurements give more valid information about the original particle size spectrum compared to the measurement of farmland, forest and pyrochar POM. This is a positive sign for research on soil microplastic; however, it does not mean that microplastic will be fully extracted from soils with this method. Soil microplastics appear within a wide range of sizes between some nanometers and its upper limit of $5 \mathrm{~mm}$ by definition. Their smallest part, fibers and microfragments produced by physical, chemical and biological erosion within the soil, might also be affected by chemical alteration due to both weathering and ultrasonication causing enhanced retention in the sedimenting fraction. Although we 
have introduced billions of metric tons of microplastics into ecosystems since the 1950s (Thompson et al., 2009; Geyer et al., 2017), there are still problems in producing microplastic fragments $<100 \mu \mathrm{m}$ on a laboratory scale with adequate use of time and material to perform experiments within this size range.

\section{Conclusion}

Unlike weathered and fresh PE, PET and PBAT microplastic, soil-derived POM like occluded POM from farm and forest soils and pyrochar concurrently shows comminution and a reduced recovery rate after ultrasonication and subsequent extraction from a sandy matrix. Applied to natural soils, parts of the farmland, forest and pyrochar POM remain within the sedimenting fraction and can be misinterpreted as more strongly bound oPOM or MOM. An overestimation as shown in this study might lead to fundamentally different interpretations of physical protection of SOM, functional carbon pools and the expected mineralization rates in consequence of, for example, land-use change. On the contrary, the extraction of microplastics neither causes additional retention of particles nor alienates the particle size spectrum due to ultrasonicdriven comminution. We conclude that density fractionation in combination with ultrasonication is an appropriate tool for analyzing occlusion of microplastics within soil aggregates and studying the size distribution of particulate microplastics.

Data availability. All of the data are published within this paper and in the Supplement.

Supplement. The supplement related to this article is available online at: https://doi.org/10.5194/bg-18-159-2021-supplement.

Author contributions. FB developed the experimental concept, extracted all samples and prepared the manuscript. GK performed the particle size analysis. AZ supported the development of the experimental concept. MK and FL supervised the whole study.

Competing interests. The authors declare that they have no conflict of interest.

Acknowledgements. Many thanks to Zoltán Mátra, who kindly helped us to conduct the QICPIC analysis.

Financial support. This open-access publication was funded by Technische Universität Berlin.
Review statement. This paper was edited by Yakov Kuzyakov and reviewed by two anonymous referees.

\section{References}

Amelung, W. and Zech, W.: Minimisation of organic matter disruption during particle-size fractionation of grassland epipedons, Geoderma, 92, 73-85, https://doi.org/10.1016/S00167061(99)00023-3, 1999.

Andrady, A. L.: The plastic in microplastics: a review, Mar. Pollut. Bull., 119, 12-22, https://doi.org/10.1016/j.marpolbul.2017.01.082, 2017.

Balesdent, J., Pétraud, J. P., and Feller, C.: Effets des ultrasons sur la distribution granulométrique des matières organiques des sols, Science du sol, 29, 95-106, 1991.

Bläsing, M. and Amelung, W.: Plastics in soil: Analytical methods and possible sources, Sci. Total Environ., 612, 422-435, https://doi.org/10.1016/j.scitotenv.2017.08.086, 2018.

Breitbach, M., Bathen, D., Schmidt-Traub, H., and Ebener, H.: Stability of adsorber resins under mechanical compression and ultrasonication, Polym. Advan. Technol., 13, 391-400, https://doi.org/10.1002/pat.203, 2002.

Büks, F. and Kaupenjohann, M.: Enzymatic biofilm digestion in soil aggregates facilitates the release of particulate organic matter by sonication, SOIL, 2, 499-509, https://doi.org/10.5194/soil-2499-2016, 2016.

Büks, F., Loes van Schaik, N., and Kaupenjohann, M.: What do we know about how the terrestrial multicellular soil fauna reacts to microplastic?, SOIL, 6, 245-267, https://doi.org/10.5194/soil-6245-2020, 2020.

de Souza Machado, A. A., Lau, C. W., Till, J., Kloas, W., Lehmann, A., Becker, R., and Rillig, M. C.: Impacts of Microplastics on the Soil Biophysical Environment, Environ. Sci. Technol., 52, 96569665, https://doi.org/10.1021/acs.est.8b02212, 2018.

Ding, L., Zhang, S., Wang, X., Yang, X., Zhang, C., Qi, Y., and Guo, X.: The occurrence and distribution characteristics of microplastics in the agricultural soils of Shaanxi Province, in north-western China, Sci. Total Environ., 720, 137525, https://doi.org/10.1016/j.scitotenv.2020.137525, 2020.

Edwards, A. and Bremner, J.: Dispersion of Soil Particles by Sonic Vibration, J. Soil Sci., 18, 47-63, https://doi.org/10.1111/j.13652389.1967.tb01487.x, 1967a.

Edwards, A. P. and Bremner, J.: Microaggregates in Soils, J. Soil Sci., 18, 64-73, https://doi.org/10.1111/j.13652389.1967.tb01488.x, 1967b.

Fuller, S. and Gautam, A.: A procedure for measuring microplastics using pressurized fluid extraction, Environ. Sci. Technol., 50, 5774-5780, https://doi.org/10.1021/acs.est.6b00816, 2016.

Geyer, R., Jambeck, J. R., and Law, K. L.: Production, use, and fate of all plastics ever made, Sci. Adv., 3, e1700782, https://doi.org/10.1126/sciadv.1700782, 2017.

Golchin, A., Oades, J. M., Skjemstad, J. O., and Clarke, P.: Study of free and occluded particulate organic matter in soils by solid state ${ }^{13} \mathrm{C}$ CP/MAS NMR spectroscopy and scanning electron microscopy, Soil Res., 32, 285-309, https://doi.org/10.1071/SR9940285, 1994.

Graf-Rosenfellner, M., Cierjacks, A., Kleinschmit, B., and Lang, F.: Soil formation and its implications for stabilization of 
soil organic matter in the riparian zone, Catena, 139, 9-18, https://doi.org/10.1016/j.catena.2015.11.010, 2016.

Graf-Rosenfellner, M., Kayser, G., Guggenberger, G., Kaiser, K., Büks, F., Kaiser, M., Mueller, C. W., Schrumpf, M., Rennert, T., Welp, G., and Lang, F.: Replicability of aggregate disruption by sonication - an inter-laboratory test using three different soils from Germany, J. Plant Nutr. Soil Sc., 181, 894-904, https://doi.org/10.1002/jpln.201800152, 2018.

Ince, N., Tezcanli, G., Belen, R., and Apikyan, I. G.: Ultrasound as a catalyzer of aqueous reaction systems: the state of the art and environmental applications, Appl. Catal. B-Environ., 29, 167176, https://doi.org/10.1016/S0926-3373(00)00224-1, 2001.

Kaiser, M. and Berhe, A. A.: How does sonication affect the mineral and organic constituents of soil aggregates? - A review, J. Plant Nutr. Soil Sc., 177, 479-495, https://doi.org/10.1002/jpln.201300339, 2014.

Kale, S. K., Deshmukh, A. G., Dudhare, M. S., and Patil, V. B.: Microbial degradation of plastic: a review, J. Biochem. Technol., 6, 952-961, 2015.

Katija, K., Choy, C. A., Sherlock, R. E., Sherman, A. D., and Robison, B. H.: From the surface to the seafloor: How giant larvaceans transport microplastics into the deep sea, Sci. Adv., 3, e1700715, https://doi.org/10.1126/sciadv.1700715, 2017.

Kayser, G., Graf-Rosenfellner, M., Schack-Kirchner, H., and Lang, F.: Dynamic imaging provides novel insight into the shape and stability of soil aggregates, Eur. Jo. Soil Sci., 70, 454-465, https://doi.org/10.1111/ejss.12796, 2019.

North, P.: Towards an absolute measurement of soil structural stability using ultrasound, J. Soil Sci., 27, 451-459, https://doi.org/10.1111/j.1365-2389.1976.tb02014.x, 1976.

O'Connor, D., Pan, S., Shen, Z., Song, Y., Jin, Y., Wu, W. M., and Hou, D.: Microplastics undergo accelerated vertical migration in sand soil due to small size and wet-dry cycles, Environ. Pollut., 249, 527-534, https://doi.org/10.1016/j.envpol.2019.03.092, 2019.

Oorts, K., Vanlauwe, B., Recous, S., and Merckx, R.: Redistribution of particulate organic matter during ultrasonic dispersion of highly weathered soils, Eur. J. Soil Sci., 56, 77-91, https://doi.org/10.1111/j.1351-0754.2004.00654.x, 2005.

Pickett, J. E.: Weathering of plastics, in: Handbook of Environmental Degradation of Materials, 163-184, William Andrew Publishing, Oxford, UK, 2018.
Pronk, G. J., Heister, K., and Kögel-Knabner, I.: Iron Oxides as Major Available Interface Component in Loamy Arable Topsoils, Soil Sci. Soc. Am. J., 75, 2158, https://doi.org/10.2136/sssaj2010.0455, 2011.

Rezaei, M., Riksen, M. J., Sirjani, E., Sameni, A., and Geissen, V.: Wind erosion as a driver for transport of light density microplastics, Sci. Total Environ., 669, 273-281, https://doi.org/10.1016/j.scitotenv.2019.02.382, 2019.

Thompson, R. C., Swan, S. H., Moore, C. J., and vom Saal, F. S.: Our plastic age, Philos. T. R. Soc. B, 364, 1973-1976, https://doi.org/10.1098/rstb.2009.0054, 2009.

Tisdall, J.: Formation of soil aggregates and accumulation of soil organic matter, in: Structure and organic matter storage in agricultural soils, Taylor \& Francis Group, London, 57-96, 1996.

von Lützow, M., Kögel-Knabner, I., Ekschmitt, K., Flessa, H., Guggenberger, G., Matzner, E., and Marschner, B.: SOM fractionation methods: relevance to functional pools and to stabilization mechanisms, Soil Biol. Biochem., 39, 2183-2207, https://doi.org/10.1016/j.soilbio.2007.03.007, 2007.

Wagai, R., Mayer, L. M., and Kitayama, K.: Nature of the "occluded" low-density fraction in soil organic matter studies: a critical review, Soil Sci. Plant Nutr., 55, 13-25, https://doi.org/10.1111/j.1747-0765.2008.00356.x, 2009.

Wells, T., Kosa, M., and Ragauskas, A. J.: Polymerization of Kraft lignin via ultrasonication for high-molecularweight applications, Ultrason. Sonochem., 20, 1463-1469, https://doi.org/10.1016/j.ultsonch.2013.05.001, 2013.

Yang, X. M., Drury, C. F., Reynolds, W. D., and MacTavish, D. C.: Use of sonication to determine the size distributions of soil particles and organic matter, Can. J. Soil Sci., 89, 413-419, https://doi.org/10.4141/cjss08063, 2009.

Zhang, G. S. and Liu, Y. F.: The distribution of microplastics in soil aggregate fractions in southwestern China, Sci. Total Environ., 642, 12-20, https://doi.org/10.1016/j.scitotenv.2018.06.004, 2018.

Zhang, S., Yang, X., Gertsen, H., Peters, P., Salánki, T., and Geissen, V.: A simple method for the extraction and identification of light density microplastics from soil, Sci. Total Environ., 616, 10561065, https://doi.org/10.1016/j.scitotenv.2017.10.213, 2018.

Zubris, K. A. V. and Richards, B. K.: Synthetic fibers as an indicator of land application of sludge, Environ. Pollut., 138, 201-211, https://doi.org/10.1016/j.envpol.2005.04.013, 2005. 